\title{
Aqueous silane-surfactant co-dispersions for deposition of hydrophobic coatings onto pre-oxidized polysilicon
}

\author{
A. Marcia Almanza-Workman ${ }^{\text {a }}$, Srini Raghavan ${ }^{\mathrm{a}, *}$, \\ Pierre Deymier $^{\mathrm{a}}$, David J. Monk ${ }^{\mathrm{b}}$, Ray Roop ${ }^{\mathrm{b}}$ \\ ${ }^{a}$ Department of Materials Science and Engineering, University of Arizona, Tucson, AZ 85721, USA \\ ${ }^{\mathrm{b}}$ Motorola Inc., Sensor Products Division, Tempe, AZ 85284 USA
}

Received 22 September 2003; accepted 30 September 2003

\begin{abstract}
The application of hydrophobic coatings onto pre-oxidized polysilicon substrates is an effective method to prevent or reduce "release" as well as "in-use" stiction in microelectromechanical systems (MEMS). A chemical system consisting of a commercially available water dispersible silane (Siliclad ${ }^{\circledR}$ ) has previously been shown to be useful in rendering polysilicon surfaces hydrophobic. In this paper, the improvement of the stability of such a chemical system is described. The objectives of the work reported in this paper are: (1) to characterize the stability of the organosilane in aqueous solutions under conditions suitable for the formation of hydrophobic coatings and (2) to investigate the influence of cationic surfactants on gelation rate of silane dispersions, on the adsorption of organosilane molecules onto pre-oxidized polysilicon and on the hydrophobic character of the coatings. Additionally, the effect of chain length and concentration for a series of alkyltrimethylammonium $\left(\mathrm{C}_{12}, \mathrm{C}_{14}, \mathrm{C}_{16}\right)$ bromide surfactants on dispersion stability has been investigated.
\end{abstract}

(C) 2003 Elsevier B.V. All rights reserved.

Keywords: Water-dispersible organosilanes; Cationic surfactants; Dispersion stability; Hydrophobic coatings; Stiction

\section{Introduction}

Surface micromachining using deposited polysilicon films is a technology that is widely used for the fabrication of microsensors and microactuators. The microstructures are released by removing the surrounding sacrificial oxide layers in a liquid-phase HF or buffered HF etch, followed by rinsing and drying. Surface machined microstructures have lateral dimensions of $50-500 \mu \mathrm{m}$, with thickness of $0.1-2.4 \mu \mathrm{m}$ and are offset $0.1-2 \mu \mathrm{m}$ from the substrate. Given their large surface area-to-volume ratio, these microstructures are particularly vulnerable to "stiction" or adhesion to the substrate and to adjacent microstructures during the release process or during use.

A very effective method to reduce or prevent stiction is to make polysilicon surfaces hydrophobic (water contact angles higher than $110^{\circ}$ ) through the formation of self-assembled monolayers (SAM) using alkyltrichlorosi-

* Corresponding author.

E-mail address: srini@u.arizona.edu (S. Raghavan). lane precursors dissolved in anhydrous organic solvents [1-3]. Self-assembling occurs by the following steps: first, the molecules react with water to form silanol-containing species. The $-\mathrm{OH}$ groups in these silanols form hydrogen bonds to each other and to surface hydroxyl groups. Interactions between the hydrocarbon chains direct chain ordering to form a dense monolayer. Finally, the organized film is covalently grafted (horizontal polymerization) by the condensation reaction of the hydroxyl groups to form $\mathrm{Si}-\mathrm{O}-\mathrm{Si}$ linkages within the monolayer and to the surface (Scheme 1(a)) [4]. Depending on reaction conditions, the formation of complete monolayers with a dense organized assembly with aligned hydrocarbon chains or the creation of a coating with disordered molecules that have not self-assembled to form condensed domains can be observed. The relative proportion of ordered and disordered phases depends on water concentration [5,6], solution age, chain length of silane molecules, temperature [7-9], silane concentration, exposure or reaction time, dispersion $\mathrm{pH}$ [10], substrate pre-treatment [11] and steric effects [12,13]. While incomplete monolayers are formed in the absence of water, excess water results in the hydrolysis and condensation of 


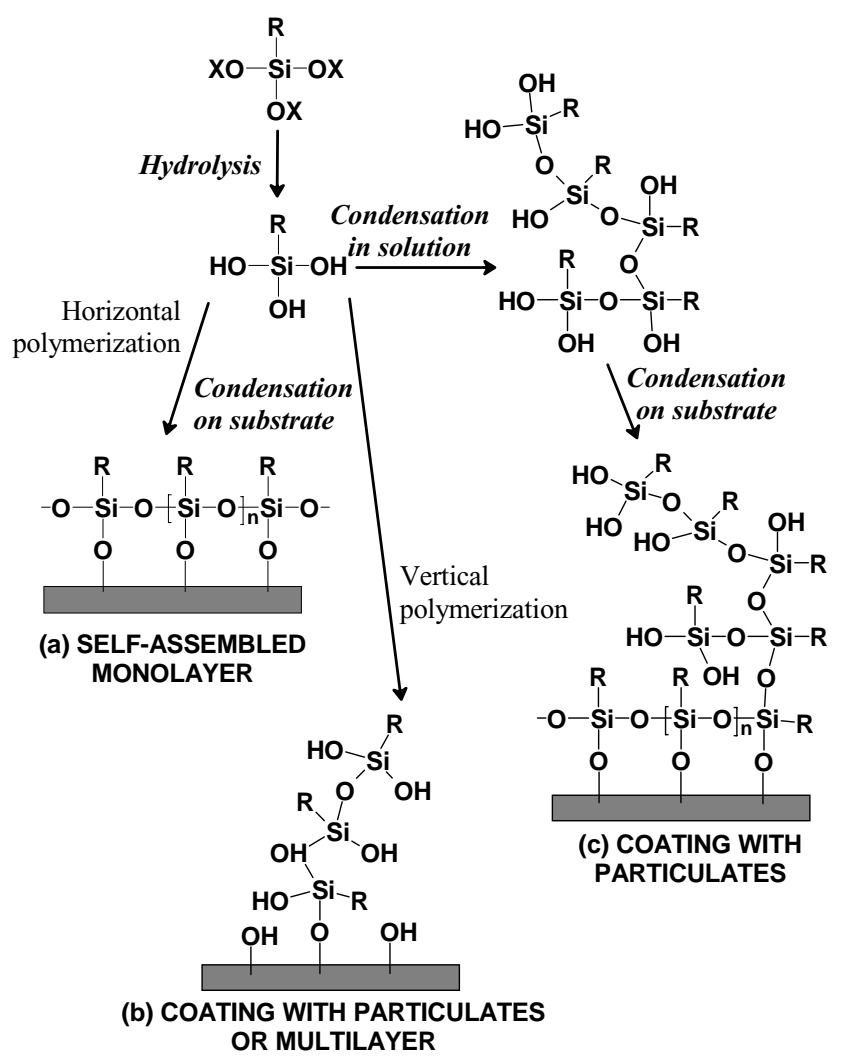

Scheme 1. Possible products of the reaction of alkytrialkoxysilanes in the aqueous phase and at the solution/substrate interface.

trifunctional silanes in the bulk liquid-phase as well as at the solution/solid interface. The complexity of this chemistry is illustrated in Scheme 1. With water as the reaction solvent, monolayer coverage of the solid surface is not generally favored. Instead, formation of particulates onto the substrate can occur due to vertical polycondensation of hydrolyzed silanes (Scheme 1(b)) or due to the deposition of aggregates $[14,15]$ formed in the aqueous phase (Scheme 1(c)) $[16,17]$.

Increasing concerns regarding the use of organic solvents in work places and the generation of organic wastes have sparked interest in the feasibility of applying highly hydrophobic coatings from water-based chemistries. The authors of this paper have shown that aqueous dispersions of a commercially available water dispersible silane (Siliclad $\left.{ }^{\circledR}\right)$ may be used to render pre-oxidized single crystal silicon [17] and polysilicon $[18,19]$ highly hydrophobic. The value of advancing $\left(\theta_{\text {adv }}\right)$ and receding $\left(\theta_{\text {rec }}\right)$ contact angles for coatings prepared by an immersion technique in dispersions containing $3 \%$ or more reactive silane at $\mathrm{pH}$ of 4 were 90 and $60^{\circ}$. Curing at $250^{\circ} \mathrm{C}$ for $5 \mathrm{~min}$ increased the advancing and receding contact angles to 117 and $85^{\circ}$. These contact angles are equal to or slightly higher than the reported values for octadecyltrichlorosilane coatings formed from an organic solvent [20] $\left(\theta_{\mathrm{adv}} / \theta_{\mathrm{rec}}=\sim 115 / \sim 85^{\circ}\right)$. Unfortunately, hydrolysis, polymerization and gelling of the water dispersible silane occurred over time resulting in increased viscosity and reduced bath life. Additionally, coatings formed from aged solutions of water dispersible silanes were not as hydrophobic as those made from freshly prepared silane dispersions. In an industrial fabrication environment, bath life as well as bath stability are critical factors. One possible way to improve the stability of water dispersible silane systems is through the use of surfactants.

In this paper, we present the results of a study that explored the effect of different cationic surfactants on the stability of aqueous Siliclad ${ }^{\circledR}$ dispersions. It is desirable that the interaction between the surfactant and silanol groups $(\mathrm{Si}-\mathrm{OH})$ of the silane molecules is strong enough to prevent or retard cross-linking but the presence of the surfactant should not interfere with the deposition of silane molecules onto the substrate. Cationic surfactants were chosen for our study because of their ability to interact with silicon dioxide over a wide solution $\mathrm{pH}$ range. The stability of silane dispersions with and without surfactant was determined by viscosity measurements. The effects of surfactant concentration on the extent of silane adsorption and on the hydrophobicity of silane coatings was studied by attenuated total reflection infrared spectroscopy (ATR-FTIR) and dynamic contact angle measurements. The role of surfactant in retarding the condensation of silanes in the aqueous solution was investigated using ATR-FTIR technique with a ZnSe crystal.

\section{Experimental}

\subsection{Materials}

A commercially available, proprietary, water dispersible octadecylsilane-based chemical $\left(\right.$ Siliclad $\left.^{\circledR}\right)$ was used in this work. This chemical, purchased from Gelest Inc., was present in a solvent system containing mixture of tertiary alcohols and diacetone alcohol at an active concentration of $20 \%$. According to the manufacturer, ${ }^{1}$ the hydrolyzed silane has a molecular weight of 332.6 and can be used for coating glass from a $0.1-1 \%$ reactive silane solution in water at a $\mathrm{pH}$ of $4-5$. The silane derivative may be described by the general formula $\mathrm{RSiX}_{3}$, where $\mathrm{R}$ is an octadecyl group $\left(\mathrm{C}_{18}\right)$ and $\mathrm{X}$ designates the proprietary hydrolyzable group attached to silicon. In the case of glass and silicon dioxide substrates, the $\mathrm{X}$ group reacts with $\mathrm{OH}$ groups on the substrate eliminating a low molecular weight compound, so that the silicon in the organosilane forms a strong chemical bond with the substrate and the alkyl group causes the surface to be hydrophobic [21].

High purity quaternary cationic surfactants with different alkyl chain length were chosen to stabilize the system with respect to polymerization and are shown in Table 1. Some properties of these surfactants are also listed in the same table. Octadecyltrimethylammonium bromide was not used

\footnotetext{
${ }^{1}$ http://www.gelest.com.
} 
Table 1

Alkyl quaternary cationic surfactants used to stabilize Siliclad ${ }^{\circledR}$ dispersions

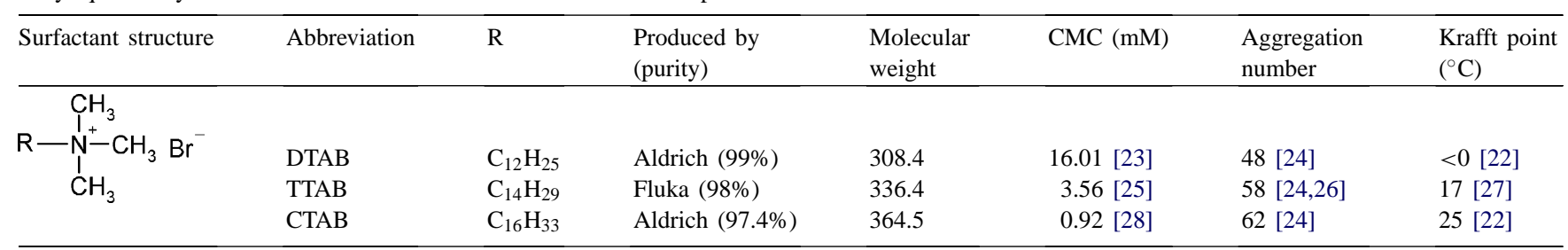

Determined experimentally using Wilhelmy plate technique; N/A: not available.

in this study because it has a Krafft temperature above $35^{\circ} \mathrm{C}$ [22], which could make it difficult for applications at room temperature.

The polysilicon samples used for coating deposition were $2 \mu \mathrm{m}$ thick LPCVD films deposited on top of Si wafers and were donated by Motorola Inc., Tempe, AZ. The films had a RMS roughness of $43 \mathrm{~nm}$.

Prior to coating deposition, the polysilicon samples were cleaned in 4:1 $\mathrm{H}_{2} \mathrm{SO}_{4}$ (98\%): $\mathrm{H}_{2} \mathrm{O}_{2}(30 \%)$ solution for $15 \mathrm{~min}$ at $\sim 90^{\circ} \mathrm{C}$ to remove organic contaminants, thoroughly rinsed in deionized (DI) water, then etched in 50:1 HF to remove the oxide film. In order to immobilize the organosilane monolayers on the substrate, the presence of $\mathrm{Si}-\mathrm{OH}$ groups on the substrate surface is required. Therefore, an oxidation treatment with $30 \% \mathrm{H}_{2} \mathrm{O}_{2}$ at $30^{\circ} \mathrm{C}$ for $15 \mathrm{~min}$ was performed before coating deposition. This treatment yielded hydrophilic surfaces with oxide layers of $18-20 \AA$ in thickness.

\subsection{Methods}

Silane dispersions were prepared by appropriately diluting the as received Siliclad ${ }^{\circledR}$ organosilane in deionized water (resistivity of $18 \mathrm{M} \Omega \mathrm{cm}$ ) containing a specific cationic surfactant when required. The $\mathrm{pH}$ of the dispersions was adjusted with hydrochloric acid, acetic acid or potassium hydroxide. The dispersions were stirred for at least $10 \mathrm{~min}$ prior to measurements or coating formation to ensure co-dispersion of surfactant and silane.

Organosilane coatings were prepared by controlled immersion and withdrawal of the polysilicon substrates in dilute aqueous dispersions of reactive silane with and without surfactant at a rate of $140 \mu \mathrm{m} / \mathrm{s}$. The coated substrates were thoroughly rinsed with DI water. Curing of the coatings was done in a convection oven (VWR model 1330 FD) for $5 \mathrm{~min}$ at a constant and pre-determined temperature.

Hydrophobicity of the coatings was characterized by measuring the contact angle of deionized water immediately after film deposition using the Wilhelmy plate technique with a dynamic contact angle analyzer (Cahn DCA312).

The stability of silane dispersions was determined by viscosity measurements using a vertical Ostwald-type viscometer $(2-10 \mathrm{cSt})$ and Ubbelohde viscometer $(7-35 \mathrm{cSt})$ immersed in a water bath set up at $30^{\circ} \mathrm{C}$. Viscosity was measured as a function of time until it could no longer be measured.

Electrokinetic measurements of coated and uncoated pre-oxidized polysilicon substrates were carried out by a flat-plate streaming potential method [29] (Fig. 1) using a BI-EKA Electrokinetic Analyzer. Polysilicon samples, cut into $7.3 \mathrm{~cm} \times 1.6 \mathrm{~cm}$ and $7.4 \mathrm{~cm} \times 1.95 \mathrm{~cm}$, were separated by a $0.25 \mathrm{~mm}$ thick Teflon sheet. A solution containing $0.01 \mathrm{M} \mathrm{KNO}_{3}$ and adjusted to the desired $\mathrm{pH}$ value was pumped through the channel formed between the plates at driving pressures of $0-250 \mathrm{mbar}$, in both flow directions. Platinized platinum electrodes [30] were used for streaming potential measurements.

ATR-FTIR was used to measure the adsorption density of DTAB and Siliclad ${ }^{\circledR}$ onto pre-oxidized silicon and to follow the condensation reaction of Siliclad ${ }^{\circledR}$ in aqueous solutions as a function of dispersion age. These measurements were carried out using a Perkin-Elmer Spectrum 2000 FTIR Spectrometer equipped with a mid-infrared deuterated triglycerine sulfate (DTGS) detector. Undoped single crystal silicon $(50 \mathrm{~mm} \times 15 \mathrm{~mm} \times 0.5 \mathrm{~mm}$, transmission range: $\left.8300-1500 \mathrm{~cm}^{-1}\right)$ and zinc selenide $(50 \mathrm{~mm} \times 10 \mathrm{~mm} \times$ $2 \mathrm{~mm}$, transmission range: $17,000-720 \mathrm{~cm}^{-1}$ ) parallelogram plates polished on both faces and beveled at $45^{\circ}$, were used as internal reflection elements (IRE). Samples were positioned into a liquid flow cell made from PTFE (Harrick Scientific model MEC-1T0). The cell was installed in a twin parallel mirror reflection attachment (Harrick Scientific Model TMP-F-PO5 $45^{\circ}$ ). Interference from atmospheric $\mathrm{H}_{2} \mathrm{O}$ and $\mathrm{CO}_{2}$ were minimized by flushing the spectrometer optics and sample compartment with ultrapure nitrogen gas.

The silicon crystal was first subjected to an oxidation treatment with $30 \% \mathrm{H}_{2} \mathrm{O}_{2}$ and then mounted in the ATR

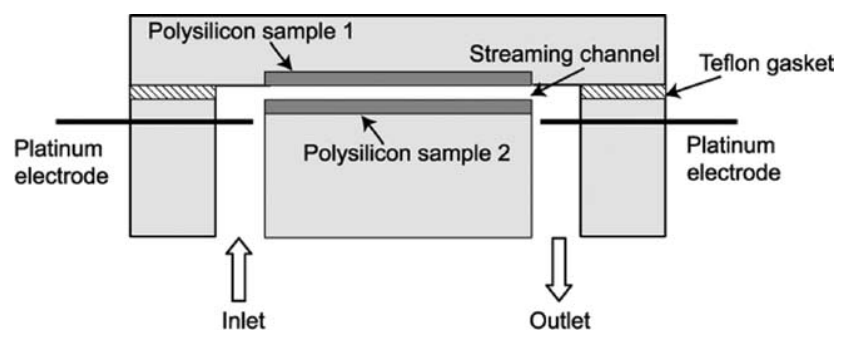

Fig. 1. Schematic diagram of the streaming potential cell. 
flow cell. The cell was flushed with DI water and a background spectrum of the $\mathrm{Si}$-water interface was taken. In experiments involving DTAB, surfactant solutions adjusted to different $\mathrm{pH}$ values were injected into the cell and spectra were recorded every minute during the first $15 \mathrm{~min}$, then less frequently for a total time of $60 \mathrm{~min}$. For Siliclad ${ }^{\circledR}$ coatings, the film was deposited onto silicon crystal by dip coating, rinsed, cured and positioned into the liquid flow cell. The IR spectra were collected at $4 \mathrm{~cm}^{-1}$ resolution and averaged over 5-15 individual scans. The calculation of adsorption density was done using the methodology described by Harrick [31] and Sperline et al. [32].

In situ condensation of Siliclad ${ }^{\circledR}$ in aqueous solutions was characterized by measuring the intensity of the $\mathrm{Si}-\mathrm{O}-\mathrm{Si}$ band near $1100 \mathrm{~cm}^{-1}$ using the ATR-FTIR technique. A $\mathrm{ZnSe}$ IRE was used for these measurements [33-35]. Prior to exposure to silane dispersions, the $\mathrm{ZnSe}$ crystal was rinsed with iso-propanol and cleaned in an UV/ozone photoreactor to remove organic contaminants. Dispersions were prepared by adding Siliclad ${ }^{\circledR}$ to DI water with or without surfactant, adjusted to $\mathrm{pH}$ of 4 with acetic acid and injected rapidly into the cell. Silane condensation was followed by acquiring spectra every minute during the first $15 \mathrm{~min}$ and then less frequently for a total time of $40 \mathrm{~h}$ in the wavelength range of $1300-800 \mathrm{~cm}^{-1}$.

\section{Results and discussion}

Initial experiments were focused on studying the stability of fresh aqueous dispersions of Siliclad ${ }^{\circledR}$ as a function of $\mathrm{pH}$ and concentration in the absence of any surfactant. The stability of dispersions containing $3 \%$ reactive silane at different $\mathrm{pH}$ values was evaluated by measuring the increase in viscosity as a function of aging time (Fig. 2(a)). The viscosity of dispersions increased slowly during the first few days and then rapidly due to condensation of - $\mathrm{OH}$ groups. This pattern of rapid increase in viscosity at the gel point is typical for thermosetting systems. The gel point was determined as the number of days it took for the viscosity to reach a value of $\sim 3 \mathrm{cSt}$ and is plotted in Fig. 2(b) as a function of $\mathrm{pH}$. The stability of Siliclad ${ }^{\circledR}$ dispersions exhibited a maximum around a $\mathrm{pH}$ of 4 . This is similar to what has been reported in literature $[10,36]$ for other alkytrialkoxysilanes. In previous studies [18], it was shown that the hydrophobicity of the coatings exhibited a maximum $\left(\theta_{\mathrm{adv}}>110^{\circ}\right)$ when deposited from dispersions adjusted to a $\mathrm{pH}$ of 4 .

The amount of reactive silane in the aqueous phase (Fig. 3) can also affect the relative rates of hydrolysis and condensation of silanes. The viscosity of dispersions containing $1 \%$ reactive silane at $\mathrm{pH}$ value of 4 reached a maximum after 15 days and no gelling was observed. However, precipitation of small particulates was observed at the bottom of the container. For the dispersion containing 3\% reactive silane, the formation of a solid gel was observed after 4 days. The viscosity of dispersions containing less than $0.1 \%$ did not

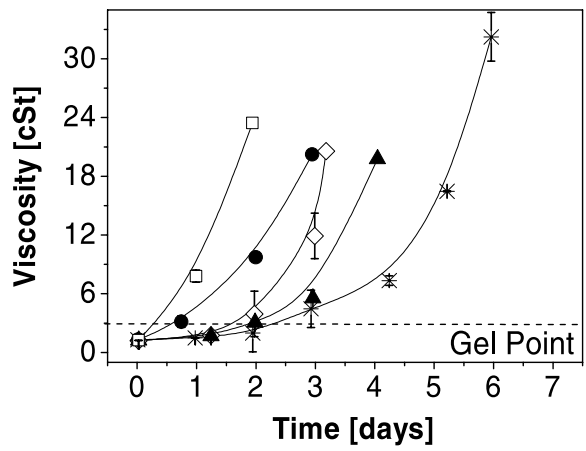

(a)
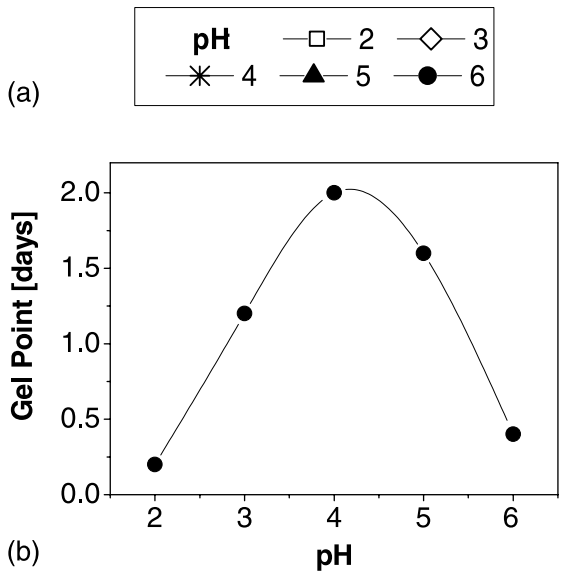

Fig. 2. Dispersion stability as a function of $\mathrm{pH}$.

change for more than 1 month, indicating that the formation of high molecular weight networks does not occur over a period of a month at very low Siliclad ${ }^{\circledR}$ concentrations.

The first set of experiments on the stability improvement of Siliclad ${ }^{\circledR}$ aqueous dispersions was to check the effect of surfactant concentration on the hydrophobic character of the coatings. The hydrophobicity of coatings deposited from

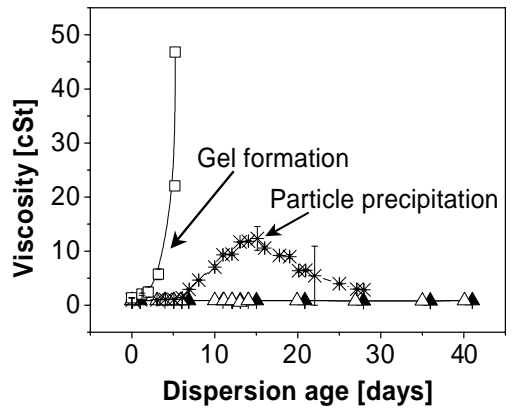

$$
\begin{aligned}
& \text { Reactive silane } \\
& \text { concentration: } \\
& -0.01 \% \\
& \triangle-0.1 \% \\
& -1 \% \\
& -\square-3 \%
\end{aligned}
$$

Fig. 3. Dispersion stability as a function of reactive silane concentration at $\mathrm{pH}=4$. 


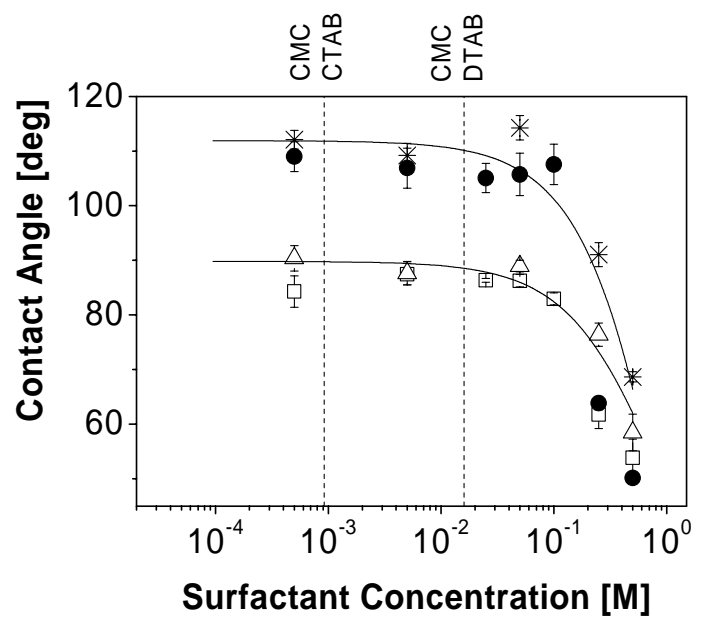

\begin{tabular}{|c|c|c|}
\hline \multicolumn{3}{|c|}{ Siliclad $^{\circledR}+$ Surfactant coatings: } \\
\hline * & DTAB & $\triangle$ \\
\hline 0 & CTAB & $\square$ \\
\hline
\end{tabular}

Fig. 4. DI water advancing contact angles of cured and uncured coatings formed from a $3 \%$ reactive silane dispersion containing different amounts of surfactant.

Siliclad ${ }^{\circledR}$ dispersions containing 3\% reactive silane and different amounts of DTAB and CTAB surfactant are shown in Fig. 4. It is pertinent to mention that the samples were rinsed prior to contact angle measurements. Interestingly, the three surfactants showed the same behavior. Highly hydrophobic coatings were obtained when the surfactant concentration was below $0.05 \mathrm{M}$. Increasing surfactant level above this concentration decreased the contact angle. This suggests that the surfactant interferes with the interaction of silane with the surface. It is possible for surfactant molecules themselves to adsorb on silicon; however, as will be shown later, increasing the amount of surfactant adsorption actually makes polysilicon more hydrophilic.

In order to characterize the influence of chain length on the stability of aqueous silane dispersions, studies were focused on dispersions that contained $0.05 \mathrm{M}$ surfactant and $3 \%$ reactive silane. Fig. 5 shows that CTAB was the most effective of all and prevented the viscosity from rising above $6 \mathrm{cSt}$ in more than 1 month, whereas the silane dispersion without surfactant turned cloudy and reached a viscosity value of $40 \mathrm{cSt}$ in less than 3 days. The stability of the silane dispersion increased by increasing the length of the hydrocarbon chain of the surfactant; this may be explained by the formation of micelles containing surfactant as well as hydrolyzed organosilane molecules. The longer the surfactant molecule, the higher the aggregation number (Table 1) and the lower the concentration at which aggregation is initiated; this may allow the formation of micelles at lower concentration with a greater number of organosilane and surfactant molecules in each micelle.
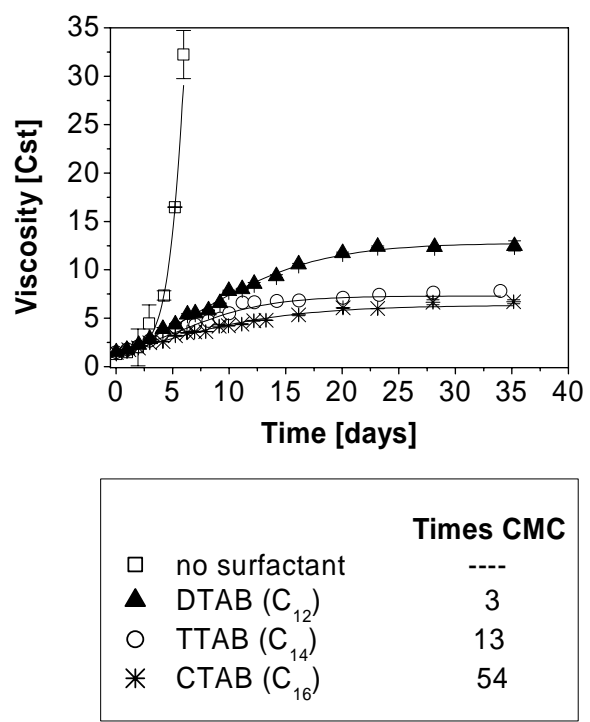

Fig. 5. Stability of silane dispersions containing 3\% reactive silane and $0.05 \mathrm{M}$ surfactant.

The role of DTAB and CTAB in retarding the condensation of silanes was investigated using ATR-FTIR technique with a ZnSe IRE. Fig. 6(a) shows the evolution of ATR-FTIR spectra of a freshly prepared $3 \%$ reactive silane
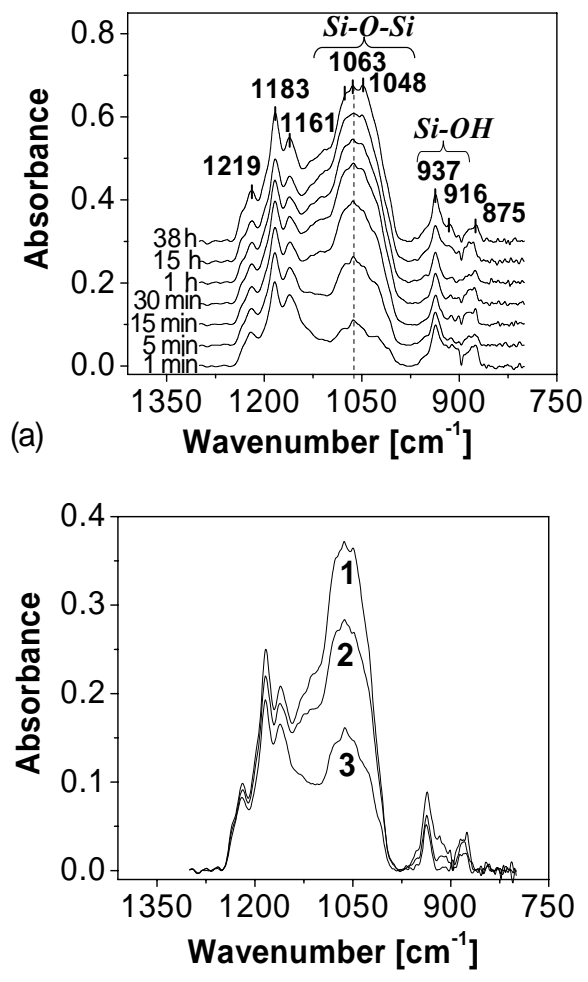

(b)

Fig. 6. ATR-FTIR spectra of $3 \%$ reactive silane (a) without surfactant as a function of dispersion age and (b) with and without surfactant aged for $4 \mathrm{~h}$. 


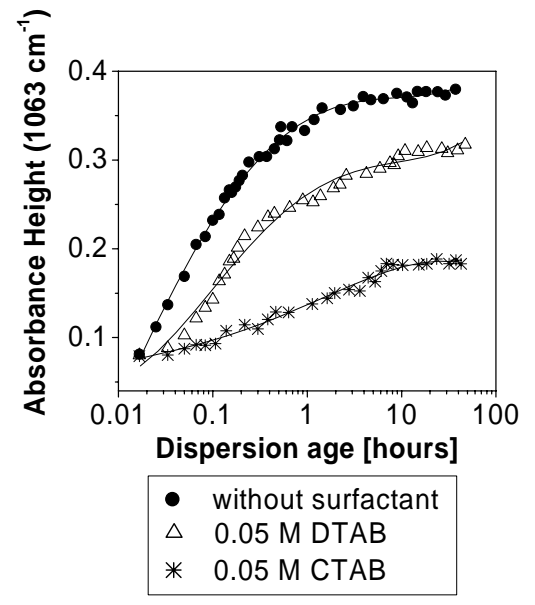

Fig. 7. Kinetics of condensation for dispersions containing $3 \%$ reactive silane with and without surfactant.

dispersion without surfactant as a function of dispersion age. Sharp bands due to $\mathrm{SiO}_{x}$ stretching modes appear in the region between 1100 and $900 \mathrm{~cm}^{-1}$ [37,38]. The bands in the range $980-890 \mathrm{~cm}^{-1}$ are associated with the $\mathrm{Si}-\mathrm{OH}$ groups [39]. The increase of the broad band centered at $1063 \mathrm{~cm}^{-1}$, which can be attributed to asymmetrical stretching of the $\mathrm{Si}-\mathrm{O}$ groups, is due to the covalent attachment with other organosilane molecules via $\mathrm{Si}-\mathrm{O}-\mathrm{Si}$ bonds. The presence of absorption bands at 1077 and $1048 \mathrm{~cm}^{-1}$ are due to the formation of longer alkylpolysiloxane chains that split the $\mathrm{Si}-\mathrm{O}$ adsorption band into two or more overlapping components [40]. The number, positions, widths and intensities of these $\mathrm{Si}-\mathrm{O}-\mathrm{Si}$ bands have been established to depend on many structural parameters, such as extent of polymerization, branching, presence and size of cyclic units, hydrogen bonding of unreacted silanols and nature of alkyl substituents on the silicon [41]. With increasing dispersion age, the intensity of the bands associated with $\mathrm{Si}-\mathrm{O}-\mathrm{Si}$ increased. It is interesting that the intensity of the $\mathrm{Si}-\mathrm{OH}$ peaks is almost constant during the aging process; this perhaps indicates that the condensation of the $\mathrm{Si}-\mathrm{OH}$ peaks to form $\mathrm{Si}-\mathrm{O}-\mathrm{Si}$ is much faster than the hydrolysis process which yields $\mathrm{Si}-\mathrm{OH}$ groups.

Fig. 6(b) shows the effect of DTAB and CTAB on the condensation of silanes in a dispersion aged for 4 hours. It should be easily discernible from this figure that the addition of surfactant decreases the intensity of the peak in the vicinity of $1063 \mathrm{~cm}^{-1}$ that is attributable to the $\mathrm{Si}-\mathrm{O}-\mathrm{Si}$ group. This clearly shows that CTAB retards more effectively the condensation of silanes. Since the structure of Siliclad ${ }^{\circledR}$ molecules is unknown due to proprietary information from the company, it is difficult to establish the exact hydrolysis mechanism.

The kinetics of Siliclad ${ }^{\circledR}$ condensation from dispersions with and without surfactant was followed through the intensity of the peak at $1063 \mathrm{~cm}^{-1}$; this is shown in Fig. 7 as a function of dispersion age. In systems containing a surfactant, the height of the $1063 \mathrm{~cm}^{-1}$ peak increased less rapidly with time. At a given dispersion age, CTAB appears
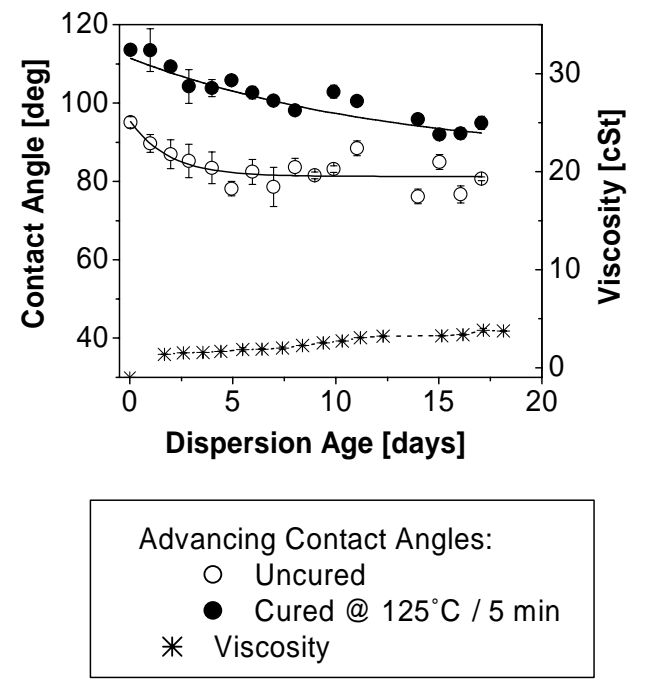

Fig. 8. Viscosity of silane dispersions containing CTAB and water advancing contact angles on coated surfaces as a function of dispersion age.

to be more effective than DTAB in retarding the formation of organosilane networks in solution.

The hydrophobicity of coatings deposited from dispersions with CTAB surfactant as a function of aging time is shown in Fig. 8. The cured films formed from freshly prepared baths yield very hydrophobic films with advancing contact angles of $114^{\circ}$. The advancing contact angle for cured films decreased from 115 to $100^{\circ}$ during the first 5 days of bath life and remained almost constant afterwards. This provides evidence that the surfactant reduced considerably the silanol cross-linking or polymerization in the micelles but did not eliminate it. The reduction on contact angle values during the first 5 days could indicate that the micelles delivered slightly reacted silanes onto the substrate. In all cases, curing improved the hydrophobicity of the coatings by at least $10^{\circ}$.

ATR-FTIR measurements using silicon IREs were carried out to determine the adsorption of Siliclad ${ }^{\circledR}$ from dispersions containing 3\% reactive silane and different amounts of DTAB. These data, obtained after a water rinse following the adsorption step, are shown in Fig. 9. It should be mentioned that the adsorption density was calculated using the absorbance of the $\mathrm{CH}_{2}$ and $\mathrm{CH}_{3}$ region. Typically, this would represent the adsorption of both DTAB and Siliclad ${ }^{\circledR}$. However, the rinsing step as will be shown in (Fig. 13(b)) would have removed most of the adsorbed DTAB. For coatings deposited from dispersions containing DTAB below its critical micelle concentration (CMC), the adsorption density was between $1.6 \times 10^{-9}$ and $1.3 \times 10^{-9}$ moles $/ \mathrm{cm}^{2}$. The adsorption density of Siliclad ${ }^{\circledR}$ decreased rapidly to values as low as $6 \times 10^{-10}$ moles $/ \mathrm{cm}^{2}$ when the surfactant concentration increased above $0.5 \mathrm{M}$. It is reported in literature $[20,42,43]$ that one hydrolyzed OTS molecule occupies an area of $0.21 \pm 0.03 \mathrm{~nm}^{2}$. Using these values and assuming that hydrolyzed Siliclad ${ }^{\circledR}$ molecules behave as OTS, a 


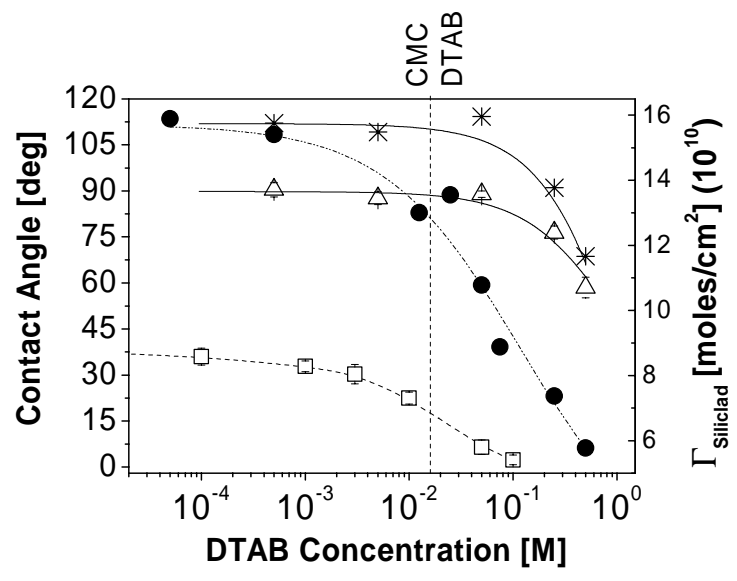

Contact Angles:
$\triangle \square$ only DTAB
$\triangle$ uncured coating
$*$ cured coating
$-\quad$ Adsorption density

Fig. 9. DI water contact angles (advancing) of cured and uncured coatings and adsorption density of Siliclad ${ }^{\circledR}$ coated samples formed from a $3 \%$ reactive silane dispersion containing different amounts of surfactant.

monolayer of Siliclad ${ }^{\circledR}$ may be calculated to be in the range $6.9 \times 10^{-10}$ to $9.2 \times 10^{-10} \mathrm{moles} / \mathrm{cm}^{2}$. Coatings deposited from silane dispersions containing small amounts of DTAB (below $0.01 \mathrm{M}$ ) appear to be thicker than a monolayer. Previous AFM studies [17] by the authors have shown that these coatings indeed contain particulates. As the surfactant concentration increased, the adsorption density decreased due to retarded condensation in solution that reduced the deposition of particulates on the substrate. For surfactant concentration greater than $0.05 \mathrm{M}$ the formation of mixed DTAB-Siliclad ${ }^{\circledR}$ coating would be expected immediately after dip coating. Rinsing would effectively remove DTAB, resulting in disordered and porous coatings with poor hydrophobicity.

A plausible mechanism for the role played by the cationic surfactant molecules is schematically shown in Fig. 10. The surfactant molecules serve two purposes: (i) prevent bulk condensation of hydolyzed silanes by forming micelles containing surfactant and silane molecules; and (ii) promote the transfer of silane molecules to the polysilicon surface by their electrostatic attraction to the oxidized polysilicon surface. The coating system is maintained at a $\mathrm{pH}$ value of 4 , where the surface of pre-oxidized polysilicon would develop a net negative charge as determined by zeta potential measurements describe below. The micelles of the cationic surfactant would be attracted to the negatively charged polysilicon surface and in that process they may be expected to transport the silane molecules to the surface. Once the hydrolyzed silane molecules are close to the surface they would react with the $\mathrm{Si}-\mathrm{OH}$ sites to form a $\mathrm{Si}-\mathrm{O}-\mathrm{Si}$ linkage with the surface. Obviously, the extent of hydrophobicity of the surface will depend upon the tightness of packing of the
Surfactant/Silane aggregation and interaction

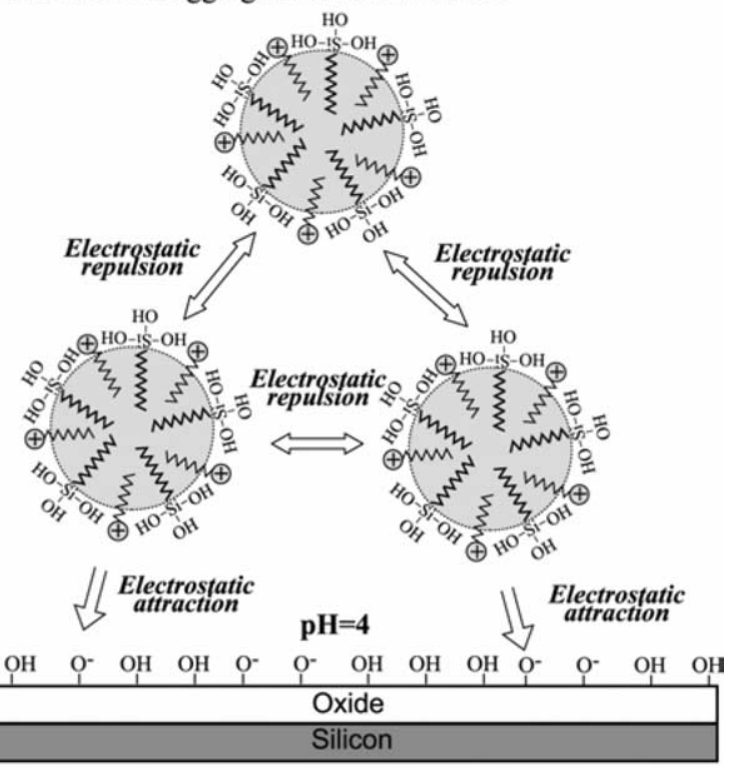

Adsorption mechanism
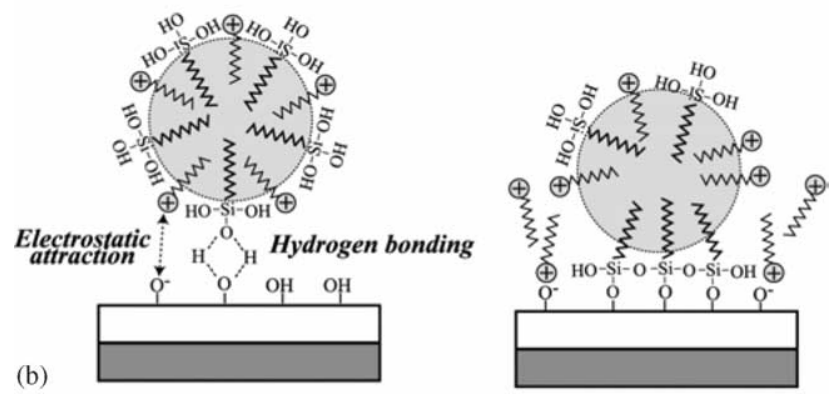

Rinsability with DI water

(c)

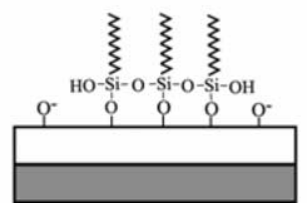

Fig. 10. Mechanism model of surfactant/silane aggregation and adsorption onto pre-oxidized silicon at a $\mathrm{pH}$ of 4 .

hydrocarbon silanes after they chemisorb onto the surface. The removal of physisorbed surfacants and excess silane is completed by a deionized water rinse.

In order to confirm the proposed adsorption mechanism in a system containing cationic surfactants and organosilanes, zeta potential measurements were carried out on pre-oxidized polysilicon in $0.01 \mathrm{M} \mathrm{KNO}_{3}$ solutions maintained at different $\mathrm{pH}$ values (Fig. 11). The point of zero zeta potential or iso-electric point (IEP) was found to occur at a $\mathrm{pH}$ of approximately 2.5 ; this is in agreement with values reported in literature for silicon oxides on single crystal silicon $[44,45]$.

The zeta potential of pre-oxidized polysilicon as a function of DTAB concentration at $\mathrm{pH}$ value of 4 is also shown 


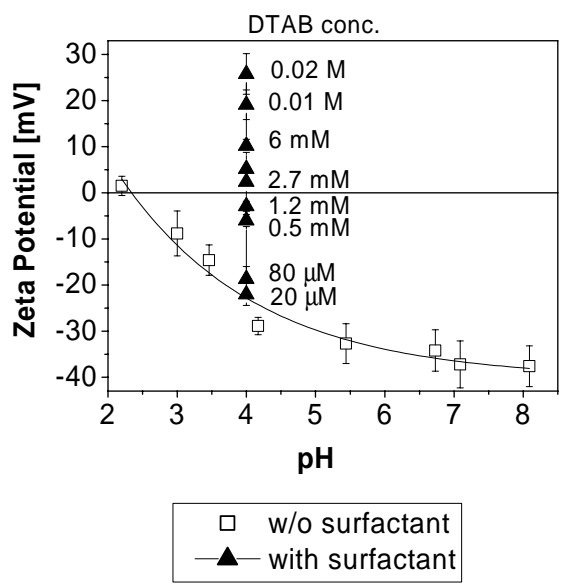

Fig. 11. Zeta potential of pre-oxidized polysilicon as a function of $\mathrm{pH}$ and DTAB concentration.

in Fig. 11. The zeta potential reversed at a concentration of $\sim 2 \times 10^{-3} \mathrm{M}$ which is below the critical micelle concentration value of DTAB. This sharp change, from negative to positive zeta potential, in cationic surfactant systems has been attributed to hemimicelle formation [46], where surface aggregates formed on the substrate reverse the overall zeta potential. The extent of adsorption of DTAB from a $16 \mathrm{mM}$ solution determined by ATR-FTIR measurements as a function of $\mathrm{pH}$ onto pre-oxidized silicon is shown in Fig. 12. The adsorption of DTAB was found to increase in the $\mathrm{pH}$ range of 2 to 5 and reached a plateau for $\mathrm{pH}$ values above 5 . This shows that at $\mathrm{pH}$ value of 4 used in the coating experiments, DTAB molecules are likely to adsorb electrostatically onto pre-oxidized silicon but the adsorption density is not at its maximum.

ATR-FTIR measurements were also done to determine the extent of DTAB adsorption onto pre-oxidized silicon. For these tests, a DTAB concentration of $16 \mathrm{mM}$ and a $\mathrm{pH}$ of 4 were chosen. After carrying out the adsorption for 1 hour the IRE crystal was rinsed with DI water. As may be noticed from Fig. 13(a), DTAB exhibited rapid adsorption in the first $10 \mathrm{~min}$ and adsorbed slowly thereafter up to a value of $2.7 \times 10^{-10} \mathrm{moles} / \mathrm{cm}^{2}$. The desorption behavior of DTAB is shown in Fig. 13(b) and is evident that most of the surfactant $\left(0.25 \times 10^{-10}\right.$ moles $\left./ \mathrm{cm}^{2}\right)$ desorbed from the surface after rinsing with deionized water for $10 \mathrm{~min}$.

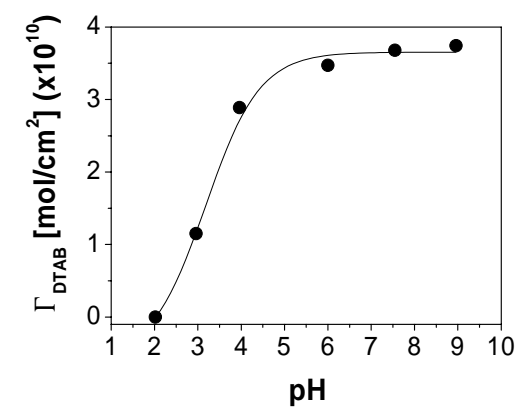

Fig. 12. DTAB adsorption density as a function of $\mathrm{pH}$.
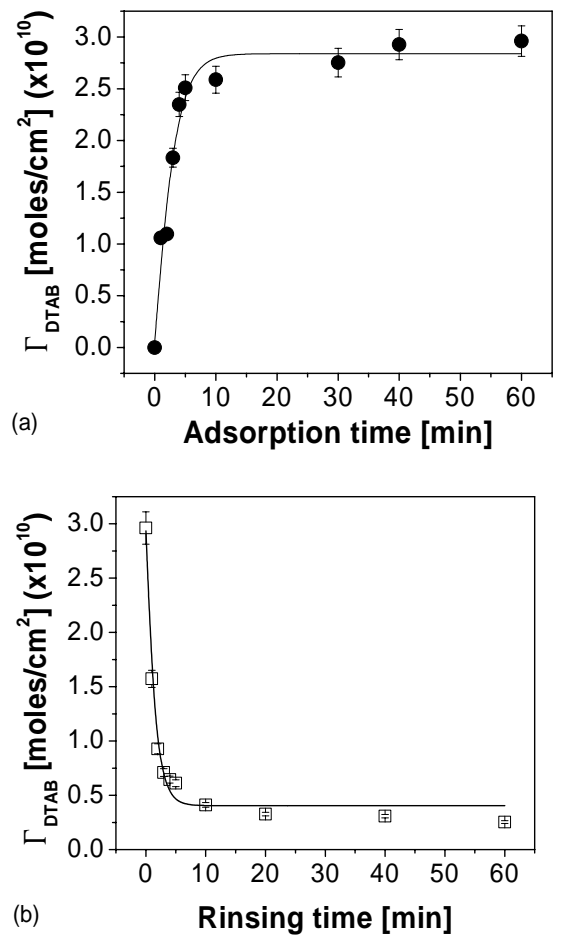

Fig. 13. (a) DTAB adsorption isotherm onto pre-oxidized silicon at $\mathrm{pH}$ of 4 and (b) amount of surfactant remaining as a function of rinsing time.

The adsorption and zeta potential data lend credibility to the mixed micelle adsorption mechanism proposed in Fig. 10. The addition of surfactants to silane dispersions provides stability against gelling of the dispersions. However, the amount of surfactant must be controlled to ensure that the hydrophobicity of the coating is not compromised. Based on the experimental conditions investigated, if the surfactant level is maintained below $0.05 \mathrm{M}$ the stability of a $3 \%$ reactive silane dispersion can be significantly increased and the coatings formed from such co-dispersion can be made highly hydrophobic.

\section{Conclusions}

This study has shown that the addition of cationic surfactants improved the stability of water dispersible silanes by retarding the formation of $\mathrm{Si}-\mathrm{O}-\mathrm{Si}$ linkages. The presence of surfactant is also beneficial in transporting the silane micelles to the surface due to their electrostatic attraction with the negatively charged surfaces. It is very clear that suitable conditions can be found in which a cationic surfactant helps to stabilize the dispersion without being detrimental to the hydrophobicity of the coating.

\section{Acknowledgements}

The National Science Foundation through the GOALI program under Grant No 9905957 funded this research. The 
authors would like to thank Roger Sperline from the Department of Chemistry at the University of Arizona for his technical assistance.

\section{References}

[1] R. Maboudian, W.R. Ashurst, C. Carraro, Sens. Actuators A Phys. 82 (2000) 219-223.

[2] U. Srinivasan, M.R. Houston, R.T. Howe, R. Maboudian, J. Microelectromech. Syst. 7 (1998) 252-260.

[3] R. Maboudian, MRS Bull. 23 (6) (1998) 47-51.

[4] M. Goldmann, J.V. Davidovits, P. Silberzan, Thin Solid Films 327-329 (1998) 166-171.

[5] D.L. Angst, G.W. Simmons, Langmuir 7 (1991) 2236-2242.

[6] P. Silberzan, L. Leger, D. Ausserre, J.J. Benattar, Langmuir 7 (1991) 1647-1651.

[7] A.N. Parikh, D.L. Allara, I.B. Azouz, F. Rondelez, J. Phys. Chem. 98 (1994) 7577-7590.

[8] R.R. Rye, Langmuir 13 (1997) 2588-2590.

[9] J.B. Brzoska, N. Shahidzadeh, F. Rondelez, Nature 360 (1992) 719721.

[10] E.J.A. Pope, J.D. Mackenzie, J. Non Cryst. Solids 87 (1986) 185198.

[11] J.D. Legrange, J.L. Markham, C.R. Kurkjian, Langmuir 9 (1993) 1749-1753.

[12] C. Carraro, O.W. Yauw, M.M. Sung, R. Maboudian, J. Phys. Chem. B 102 (1998) 4441-4445.

[13] D.W. Britt, V. Hlady, J. Colloid Interface Sci. 178 (1996) 775-784.

[14] S. Brandriss, S. Margel, Langmuir 9 (1993) 1232-1240.

[15] B.C. Bunker, R.W. Carpick, R.A. Assink, M.L. Thomas, M.G. Hankins, J.A. Voigt, D. Sipola, M.P. de Boer, G.L. Gulley, Langmuir 16 (2000) 7742-7751.

[16] A.Y. Fadeev, T.J. McCarthy, Langmuir 16 (2000) 7268-7274.

[17] A.M. Almanza-Workman, S. Raghavan, S. Petrovic, B. Gogoi, P. Deymier, D.J. Monk, R. Roop, Thin Solid Films 423 (2003) 77-87.

[18] A.M. Almanza-Workman, S. Raghavan, P. Deymier, D.J. Monk, R. Roop, J. Electrochem. Soc. 149 (2002) H6-H11.

[19] A.M. Almanza-Workman, S. Raghavan, P. Deymier, D.J. Monk, R. Roop, Sol. State Phenom. 76-77 (2001) 23-26.

[20] S. Ge, A. Takahara, T. Kajiyama, J. Vac. Sci. Technol. A Vac. Surf. Films 12 (1994) 2530-2536.
[21] F.V. Allan, P.Y. Hsieh, US Patent 3,728,008 (1973) 4 pp.

[22] T.W. Davey, W.A. Ducker, A.R. Hayman, J. Simpson, Langmuir 14 (1998) 3210-3213.

[23] H.B. Klevens, J. Phys. Chem. 52 (1948) 130-148.

[24] S.P. Moulik, M.E. Haque, P.K. Jana, A.R. Das, J. Phys. Chem. 100 (1996) 701-708.

[25] R.L. Venable, R.V. Nauman, J. Phys. Chem. 68 (1964) 3498-3503.

[26] R.G. Alargova, I.I. Kochijashky, M.L. Sierra, R. Zana, Langmuir 14 (1998) 5412-5418.

[27] E.S. Blackmore, G.J.T. Tiddy, J. Chem. Soc. Faraday Trans. I 84 (1988) 1115-1127.

[28] M. Czerniawski, Roczniki Chemii 40 (1966) 1935-1945.

[29] P.J. Scales, F. Grieser, T.W. Healy, L.R. White, D.Y.C. Chan, Langmuir 8 (1992) 965-974.

[30] A.M. Feltham, M. Spiro, Chem. Rev. 71 (1971) 177-193.

[31] N.J. Harrick, Internal Reflection Spectroscopy, second ed., Harrick Scientific Corp., New York, 1979.

[32] R.P. Sperline, S. Muralidharan, H. Freiser, Langmuir 3 (1987) 198202.

[33] D.E. Leyden, R.S.S. Murthy, J.B. Atwater, J.P. Blitz, Anal. Chim. Acta 200 (1987) 459-468.

[34] M.I. Tejedor-Tejedor, L. Paredes, M.A. Anderson, Chem. Mater. 10 (1998) 3410-3421.

[35] D.E. Leyden, J.B. Atwater, J. Adhes. Sci. Technol. 5 (1991) 815-829.

[36] E.R. Pohl, F.D. Osterholtz, Polym. Prepr. Am. Chem. Soc., Division Polym. Chem. 24 (1983) 200-201.

[37] A.N. Parikh, M.A. Schivley, E. Koo, K. Seshadri, D. Aurentz, K. Mueller, D.L. Allara, J. Am. Chem. Soc. 119 (1997) 3135-3143.

[38] D.G. Kurth, T. Bein, Langmuir 11 (1995) 578-584.

[39] H.O. Finklea, L.R. Robinson, A. Blackburn, B. Richter, D. Allara, T. Bright, Langmuir 2 (1986) 239-244.

[40] K.I. Iimura, T. Kato, Colloid Surf. A Physicochem. Eng. Asp. 171 (2000) 249-264.

[41] R. Maoz, J. Sagiv, D. Degenhardt, H. Moehwald, P. Quint, Supramol. Sci. 2 (1995) 9-24.

[42] S.R. Wasserman, Y.T. Tao, G.M. Whitesides, Langmuir 5 (1989) 1074-1087.

[43] R. Banga, J. Yarwood, A.M. Morgan, B. Evans, J. Kells, Thin Solid Films 284-285 (1996) 261-266.

[44] W. Rudzinski, R. Charmas, W. Piasecki, B. Prelot, F. Thomas, F. Villieras, J.M. Cases, Langmuir 15 (1999) 5977-5983.

[45] Y. Duval, J.A. Mielczarski, O.S. Pokrovsky, E. Mielczarski, J.J. Ehrhardt, J. Phys. Chem. B 106 (2002) 2937-2945.

[46] R.W. Smith, T. Soc. Min. Eng. 254 (1973) 353-357. 